\title{
Evaluation of Visuo-Spatial Perspective Taking Skills using a Digital Game with Different Levels of Immersion
}

\author{
Laura Freina ${ }^{1}$, Rosa Bottino ${ }^{1}$, Mauro Tavella ${ }^{1}$, Carlo Chiorri ${ }^{2}$ \\ ${ }^{1}$ National Research Council - Institute for Educational Technologies, Genova, Italy \\ \{Freina, Bottino,Tavella\}@itd.cnr.it \\ 2 University of Genova - DISFOR, Genova, Italy \\ carlo.chiorri@unige.it
}

\begin{abstract}
The present paper presents the results of an experiment aimed at assessing the impact of different levels of immersion on performance in a Spatial Perspective Taking (SPT) task. Since SPT is an embodied skill, the hypothesis was that the more immersive a tool is, the better the performance should be. Ninety-eight students from a local primary school have played with three different versions of a game: (i) completely immersive with a Head Mounted Display, (ii) semi immersive on a computer screen and (iii) non-immersive where no movements were possible for the player. Results showed that in the immersive versions of the game, players obtained higher scores than in the non-immersive version, suggesting that an immersive tool can better support performance in a SPT task.
\end{abstract}

Keywords: Spatial Perspective Taking, Virtual Reality, Immersion, Spatial Reasoning;

\section{Introduction}

In the European Union, there is evidence of skills shortages in STEM (Science, Technology, Engineering, and Mathematics) while around 7 million new jobs are forecast until 2025 in this sector [1]. Therefore, there is a strong need to prepare young people for a future that will require good scientific knowledge and a good understanding of technology. A positive start, at an early age is crucial for the subsequent formation of positive attitudes towards science [2]. Furthermore, the development of some basic abilities, among which spatial reasoning, has been proved to have a positive correlation with academic success in mathematics and science [3].

Newcombe [4] reports several different longitudinal studies that started back in the fifties that followed the development of a large number of American children from nursery school all the way to adulthood. These studies have shown a close correlation between spatial reasoning skills and school results in STEM subjects.

Supporting the development and consolidation of spatial reasoning in primary school children can thus have a positive and long lasting impact on their lives. Spatial reasoning is a complex skill, made of many components such as the ability to imagine and manipulate objects in space, the ability to navigate a map, to estimate the position of a hidden object, etc. Among these, Spatial Perspective Taking (SPT) is the ability of imagining how the world looks like from another person's point of view, which is important for orientation in space. As Uttal at al. have shown [5], spatial reasoning can get better with a specific training, with durable and transferable results.

Several studies [6-10] have shown the advantages of the use of certain games in education as a way to increase involvement and motivation both in children and adults. However, many authors point out that the real advantage of the use of digital games in education go well beyond mere motivation [11-12].

A number of significant research studies investigated from different perspectives the relationship between different kinds of digital games and specific learning objectives. Several authors [13-15] argue that the use of educational digital games has a significant positive impact on children's cognitive abilities, and, some studies, in particular, examine the positive impact on skills related to reasoning, logic and mathematics [16-17]. 
The potential effectiveness of digital games for learning is strictly linked to specific design and interface choices. Indeed, different computer implementations of the same game can have different degrees of educational impact.

This paper describes and reports the results of an experiment that was set up to investigate interface impact on the development of the SPT ability [18]. A digital game was developed in three different versions (which correspond to three different level of immersion) and then used with about one hundred primary school students.

The analysis of the collected data shows that the statistically weaker performance was obtained in the non-immersive version of the game, while in the other two conditions the performances did not significantly differ. In the paper, results from the experiment are discussed in details and further developments of the research studies are then briefly introduced.

\section{Immersive Virtual Worlds}

Virtual reality is defined as an artificial environment that is experienced by the player through sensory stimuli and with which it is possible to interact in a natural manner using electronic tools. In virtual reality, the concepts of "spatial immersion" and "presence" are often used and sometimes there is confusion between the two.

"Spatial immersion" is defined as an objective property that refers to the technical capability of the system to deliver a surrounding and convincing environment. This can be obtained through the use of a Head Mounted Display (HMD) where two screens are placed in front of each eye in order to obtain a stereoscopic view of the scene. When this is used along with headphones, the player perceives the virtual world through the eyes and ears in a very similar manner as the real one.

"Presence" is the human response to a virtual environment. Presence is therefore the extent to which participants believe they are somewhere different from their actual physical location [19]. This is usually linked to spatial immersion, but presence can also occur in other contexts, for example while reading when we are deeply involved in the story of a book.

As Dalgarno and Lee state "3-D Virtual Learning Environments can be used to facilitate learning tasks that lead to the development of enhanced spatial knowledge representation of the explored domain. (p.18)" [20]. Furthermore, learning in a virtual world that is recognized as authentic by the learner makes learning transfer to the real world easier [21]. In the virtual world, the players can actually make the physical movements that are characteristic to the abilities that they are practicing, supporting a kinaesthetic approach to learning.

\section{Visual Reasoning and Spatial Perspective Taking}

Visual and spatial skills are fundamental in order to be able to find our orientation in space, perceive objects around us and organize them into a coherent visual scene, mentally imagine an object that is not physically present.

Newcombe and Frick [22] define SPT as the ability to correctly identify the position and rotation of a person in space and understand that their perspective can be different from ours. It is the ability to imagine ourselves in the place of another person and be able to predict what will be seen after the corresponding movement in space. It involves occupying the place of the other person and understanding the relative position of objects.

Kessler and Rutherford [23] argue that even though SPT is a high-level cognitive process, it is not a purely abstract transformation of a reference frame or of a coordinate system, as it had been the established view within linguistics/computational linguistics [24]. Rather, it relies on actionrelated and proprioceptive representations of the body. These findings have been confirmed by Surtees et al. [25], whose experiment demonstrated that SPT is an embodied process: when people are asked to state what another person sees, they actually imagine moving to the new position in space and then they reconstruct the view from there. While doing so, they activate those parts of the brain that are involved with movements in space. Due to the embodied component of the SPT skill, training in an immersive virtual world may have a positive impact on performance. Virtual worlds can offer different levels of "immersion", by surrounding the users to make them feel as if they were "really there".

SPT in children has been investigated by Piaget [26], according to whom its complete development does not take place before the age of 10, but later studies [27] suggested that the 
ability actually develops some years earlier. According to Surtees et al. [25], there are two different levels of SPT skills: the first level, which usually develops in children when they are about five, allows understanding if a given object can be seen from a different point of view. The second level, which usually develops some years later, between the age of 6 and 8, makes it possible to imagine how a given scene would look like from a different perspective. Mayer et al. [28] have found a big difference in mathematical reasoning skills between second and third graders: up to grade two they are closely related to language skills, but starting from grade three spatial reasoning can predict both mathematical reasoning and numerical operations skills. According to Newcombe [4], the SPT skill, completes its development in the first years of primary school.

Grounding on these studies, the best moment for a specific intervention aimed at potentiating spatial reasoning appears to be in the last years of primary school; therefore, an experiment was set up with a group of children between the age of 8 and 10 (corresponding to grades three and four).

\section{The "In Your Eyes" Game}

The "In Your Eyes" game [29] takes place in a virtual living room (Figure 1), with a square table in the middle. Four screens on the wall show the pictures of the table taken from the four sides, and the coloured frames of the screens are used to identify them easily. In the room, a Non-Player Character (NPC) welcomes the players and helps them along the whole game. After putting some objects on a table, the NPC moves to one of the four sides of such table, and the player has to pick the screen that shows the table from the NPC's point of view. The goal of the game is to train the players to recognize the table from the NPC's perspective. Before answering, the players are free to move in the room so that they can see the table and the objects from every possible angle, but they have to go back to the play position before giving the answer.

Each correct answer gives the player a maximum of 9 points, which are decreased by 3 at each error and by 1 at each exploration out of the play area. At each mistake, the wrong answer is blackened (the screen is switched off), and a brief hint is given.

At any moment, the players are free to move, they can go behind the NPC to check what the table looks like from there. This allows them to decide autonomously how much help they need. In this manner, as stated by the scaffolding theories [30], the players are provided with all the support they may need to solve a problem that is a little beyond their capabilities without any help. As their skills improve, the quantity of help they will ask will decrease up to the moment when they will be able to play by themselves.

The game was originally developed as a tool to support the acquisition and consolidation of the SPT skill. Each scene was generated at runtime by choosing randomly some objects from a pre-defined set and placing them on the table according to a set of rules in order to avoid them from overlapping. Since, in this experiment, our aim was measuring how immersion impacts on performance, a fixed sequence of twelve different scenes was defined, with one, two, or three objects on the table. The number of scenes was limited by the need to keep the play sessions rather short: Nicols [19] suggests that keeping the length of each play session around 10 minutes can limit sickness issues in teenagers and young adults.

The assignment of the correct answer to a coloured screen on the wall is left random so that it changed each time the scene was played to minimise the risk that the children would just remember the sequence of the correct answers from one session to the next. 


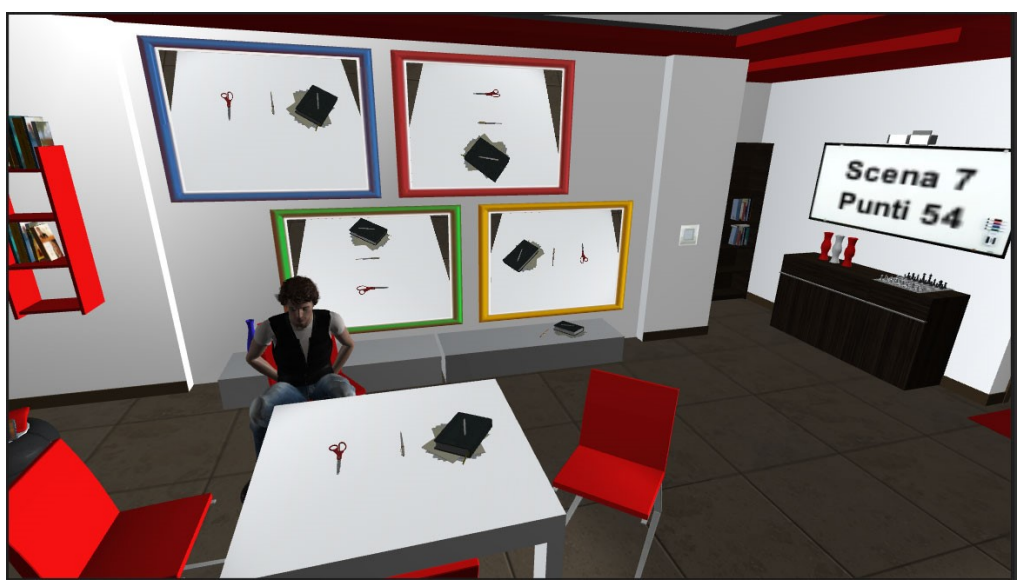

Figure 1. The Virtual Room of the "In Your Eyes" game.

Special attention was paid to the instructions given to the player. It is possible to solve the given task in two different ways: imagining either to move to the NPC's position and reconstructing the scene from there, or to turn the table round until the side where the NPC sits is in front of us. The two different approaches involve two different abilities: SPT in the former case and Object Rotation ability in the latter. The two skills are different and performance can vary a lot in the same participants. Inagaki et al. [31] have demonstrated that just by giving different instructions, with the same experimental setting, it is possible to stimulate the participants to use one skill or the other.

We wanted the children to use the SPT skill, therefore, the NPC asked the player to "imagine you are by my side and tell me what the table looks like from here". Furthermore, Tversky found that "... The mere presence of another in the scene with the potential for action elicits taking that person's perspective. (p.125)" [32]. The NPC's body sitting at the tableside and looking at the scene should promote the use the SPT skill.

The game, which was developed using Unity 3D with Oculus Rift in its SDK2 version [33], is available in three different versions, addressing different immersion levels:

- Immersive (Im-version): using a HMD, the players feel as if they actually were inside the living room where they can freely move around as they wish.

- Semi-immersive (SI-version): the players can still move freely, they see the virtual living room on a normal computer screen, they can explore but the feeling of actually "being there" should be reduced.

- Non-immersive (NI-version): there is a fixed view on the living room showing the table, the $\mathrm{NPC}$ and the pictures on the wall. No exploration is possible.

\section{The Experiment}

In order to assess if, and to what extent, immersion actually supports better performance in the SPT task, an experiment was set up with six classes from a local primary school in Genova (Italy). The main research question was to assess if there is a correlation between the immersion level of the game and performance in the SPT task.

In our hypothesis, the best performance should be measured in the complete immersive version of the game since having the possibility to "dive" into the virtual world should allow the players to:

- Understand the task more easily by exploring the scene and testing the hypothesis;

- Build a better mental model of the scene and the involved objects by freely moving around the table and examining the objects from all the possible perspectives;

- Manage by themselves the amount of help needed: it is always possible, at any time of the game, to move to the other side of the table and see what the scene looks like;

- Increase their motivation and involvement in the game by freely exploring the virtual world.

However, using a HMD could be tiring and it could cause sickness to some players; a greater effort in managing an interface the players are not used to may be needed. Furthermore, the 
presence of a virtual environment in which to move and explore, can draw the attention away from the main task and therefore influence performance negatively.

Six elementary classes were chosen: four third grade classes (8-9 year olds) and two fourth grade classes (9-10 year olds). A meeting was organized with the families to present the project and show them the three game versions. Informed consent was then signed and the authorized children were enrolled in the experiment.

The participants were 101, 60 boys and 41 girls aged from 8 years and 2 months to 10 years and 7 months, with an average age of 9 years and 1 month at the beginning of the experiment. Three participants dropped out before the end of the experiment leaving 98 participants.

Participants' ability in the SPT task was measured at the beginning of the project using a paper based pre-test developed following literature in the field [34] (Figure 2). A repeated measures design was chosen for the experiment, so that each child used all the three versions of the game with the same fixed sequence of scenes. Balanced groups with respect to the SPT skill, sex and age were made in order to counterbalance results and avoid order effects.

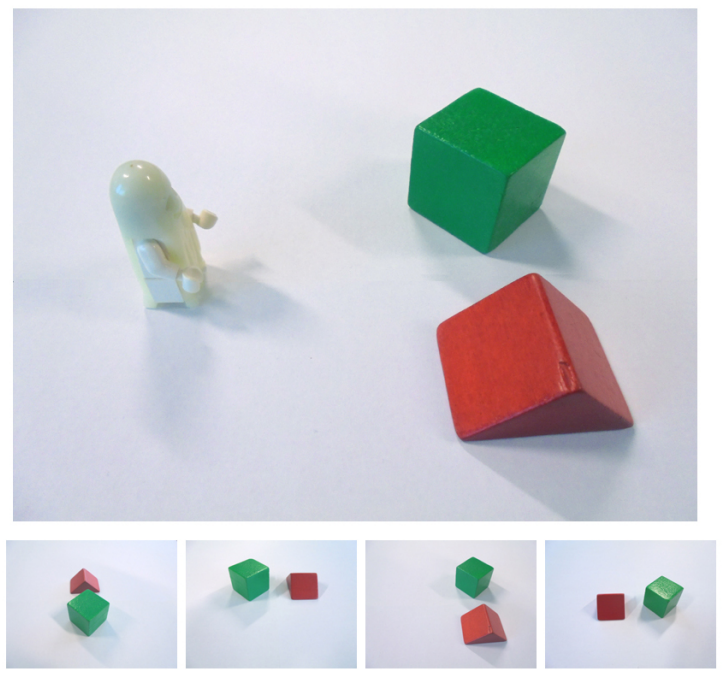

Figure 2. The paper based test. The participant has to select from the bottom pictures the one that shows the scene as the little ghost sees it.

Each participant played three times, one for each game version available. The three sessions were separated by a period of at least two weeks to minimize the memorization of the sequence of scenes.

One of the objectives of the experiment was to assess if a higher level of immersion would generate a higher feeling of presence and if the feeling of presence actually correlated with the performances in the task. For this reason, a short questionnaire based on the one used by Slater [35] measuring a self-reported subjective feeling of presence in the virtual world was defined. The three original questions have been translated into Italian paying attention to make them comprehensible to the target age group. Question 3: "The computer generated world seems to me to be more like something that I saw / somewhere that I visited" proved to be difficult to understand and was dropped. The remaining two questions have been measured on a seven-point Likert rating scale.

- Q1: Did the game make you feel as if you were physically inside the living room? (not at all very much)

- Q2: Were there times during the game when the living room became real and you nearly forgot about the real world? (never - nearly always)

Each participant played with the game individually, always in presence of a researcher, leaving the class for the play session. At the end of the session, the presence questionnaire was filled in and the student returned to class. After the last session, the researcher asked orally to each participant "Which version of the game did you like best? Which one do you think works better?" 


\section{Results and discussion}

About $11 \%$ of the sample stopped playing with the Im-version before the end of the session, because of sickness issues. The incomplete sessions (i.e. those in which the player did not play all the 12 scenes) were considered in the data analysis.

As far as the personal enjoyment of the game is concerned, at the end of the last play session $67 \%$ of the participants have answered that they preferred the Im-version; another $29 \%$ had no preference. Only about 3\% preferred the SI-version while only $1 \%$ preferred the NI-version. It should be noted that, even if not considered in these percentages, some participants who stopped playing with the Im-version because they were sick, still preferred it to the other ones. Apparently, immersion can be good for motivating students, even though all participants were at their first or second trial of an immersive device and they were enthusiastic about the novelty as such.

\subsection{Data analysis}

During the experiment, the software automatically traced, for each player, the following data: version of the game (which defines the immersion level); number and duration of each play session; score, number and type of errors for each scene. Scores at the pre-test were also analysed. Game score and number of errors were considered as a measure of the players' performance. In the analysis, the repeated-measure factor (i.e., immersion level) was tested controlling for the following covariates: grade, gender, school marks in math, geometry, and science, pre-test scores, duration of the performance, score at Q1 and Q2, session in which the condition was experienced (first, second, or third), immersion level by session interaction.

Eighty-four participants $(86 \%)$ completed all the three conditions, while the remaining completed only two conditions. In a "classical" linear model, these latter participants would be excluded from the analysis, since all cases should have valid scores on all the levels of the factor. However, linear mixed modelling (LMM) addresses this issue as it does not require participants to be measured on the same number of levels of a factor. Hence, we allowed a multilevel structure to data, in which scores in each immersion level (Level 1) were nested into participants (Level 2), which, in their turn, were nested into classrooms (Level 3). LMM also addresses the issue of nonindependence of participants' scores at each measurement occasion and in each classroom [36]. LMM models were tested using the $\mathrm{R}$ packages lme4 [37], lmerTest [38], and LMERConvenienceFunctions [39].

\subsection{Results}

The main effect of immersion level on test score was significant $(F(2,195.23)=9.07, p<.001)$. Post-hoc tests showed that in both Im- and SI-version conditions, scores were significantly higher than in the NI-version, but they did not differ within each other (Figure 3).

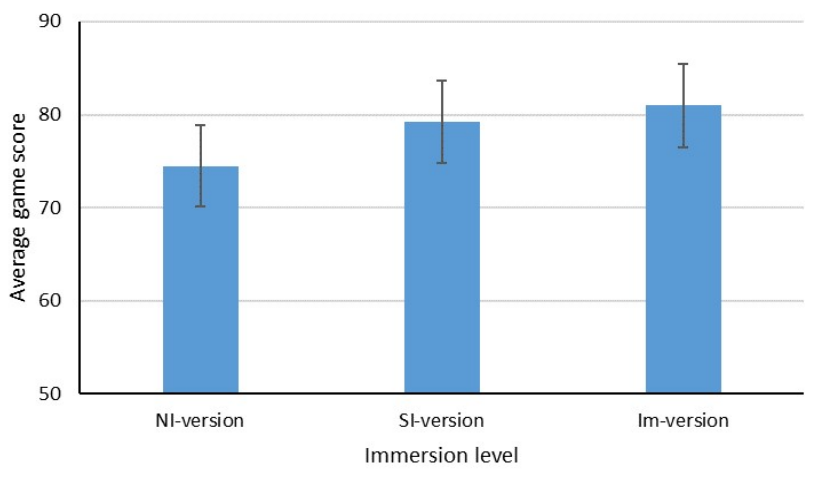

Figure 3. Global average game scores

The lack of differences between Im- and SI-version can be explained considering that both allow players to move near the NPC and see the table from his point of view, while this is not possible in the NI-version. Nevertheless, the immersion as such appears not to have a great influence on the players' performance, even if this may also be due to the fact that all the 
participants were at their first experience wearing a headset, and therefore were not so good at managing the new interface.

We also observed: (i) a significant positive effect of the pre-test score (i.e., higher pre-test scores, better performance; $\mathrm{F}(1,91.54)=48.54, \mathrm{p}<.001)$, suggesting that players with a higher ability in a SPT task also obtained higher scores in the game, regardless of the immersion level; (ii) a significant negative effect of the duration of each play session (i.e., longer duration, worse performance; $\mathrm{F}(1,245.86)=15.65, \mathrm{p}<.001)$, indicating that when the player's ability is weaker, it takes more time to imagine the change in perspective; and (iii) a significant effect of the session $(\mathrm{F}(2,180.35)=7.28, \mathrm{p}<.001)$, suggesting that, regardless of the immersion level, performing a task as the first, second, or third had an effect on game score. Post-hoc tests revealed that scores at session 1 were significantly lower than those at session 2 and 3, which, in their turn, did not significantly differ (Figure 4).

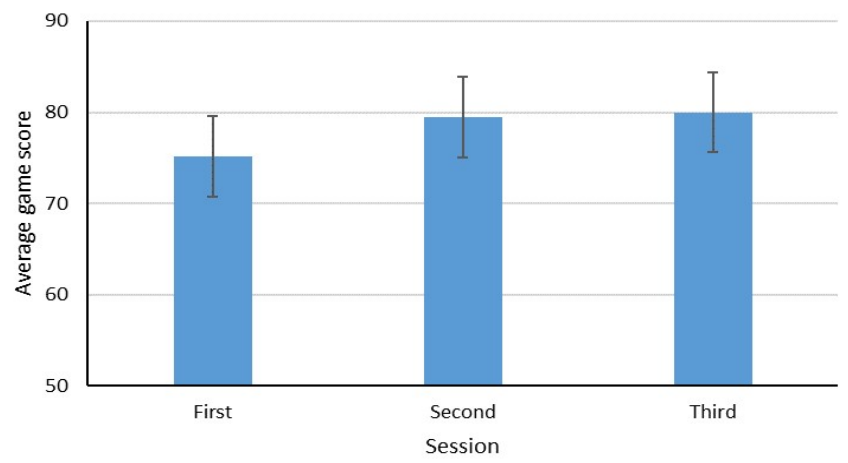

Figure 4. Average score per session

This result can be explained considering that during the first play session, participants did not have a clear idea of the task, and therefore more mistakes were made. By the time they got to the second session, the task was understood and improvements due to training were no longer significant at the third session, also because of the very short duration of each play session: only twelve scenes for a global play time of 10-15 minutes. It is noteworthy that the interaction immersion level by session was not significant $(\mathrm{F}(4,240.52)=0.39, \mathrm{p}=.818)$.

\subsection{Subjective feeling of presence}

After each play session, the players answered the two questions about their subjective feeling of presence in the virtual room. A LMM similar to the one for game score was specified (except, of course, that scores on Q1 and Q2 were not entered as covariates). For Q1 ("Did the game make you feel as if you were physically inside the living room?"), we observed a significant effect of immersion level $(\mathrm{F}(2,190.16)=36.21, \mathrm{p}<.001)$ and session $(\mathrm{F}(2,175.63)=10.55, \mathrm{p}<.001)$. Post-hoc tests revealed that the Im-version obtained significantly higher ratings that the other two conditions (regardless of the session), and that the first session obtained significantly higher ratings that the other two sessions (regardless of the immersion level; Figure 5). 

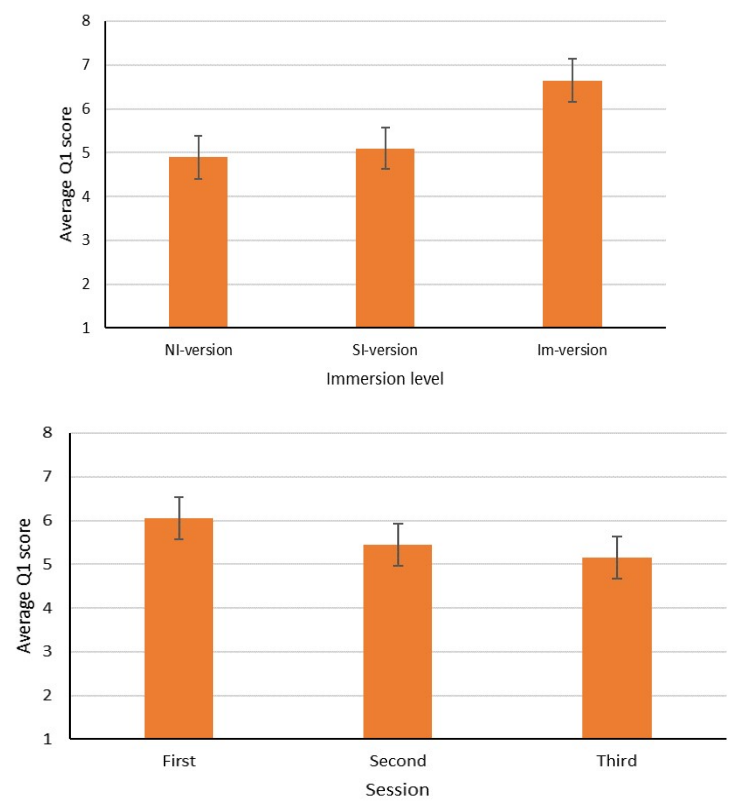

Figure 5. Presence question: Q1: Did the game make you feel as if you were physically inside the living room? $(1=$ 'not at all' -7 = 'very much').

It should also be noted that the mean rating for Q1 in the Im-version was not statistically different from the higher score (7). Taken together, these results suggest that immersion has an important impact of the feeling of being physically present in the virtual world.

For Q2 ("Were there times during the game when the living room became real and you nearly forgot about the real world?"), only the main effect of immersion level was statistically significant $(\mathrm{F}(2,193.03)=12.39, \mathrm{p}<.001)$. Post-hoc revealed that the Im-version obtained higher ratings than the other two conditions (Figure 6).

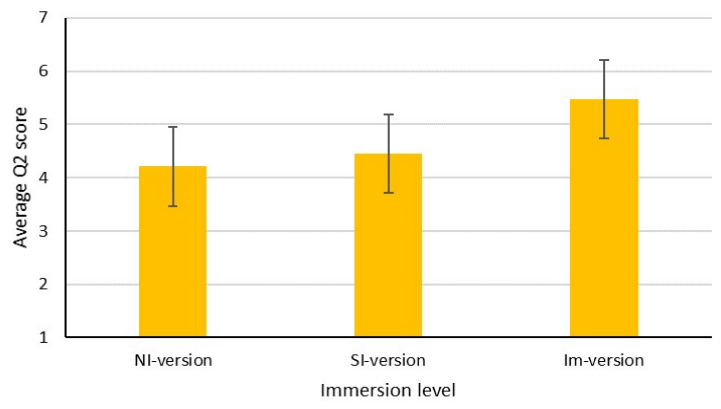

Figure 6. Presence question: Q2: Were there times during the game when the living room became real and you nearly forgot about the real world? $(1=$ never' $-7=$ 'nearly always' $)$.

Interestingly in Q2, especially for the SI-version and the NI-version, we observed a high number of 1-answers. This is because these versions are experienced on the computer screen, and the surrounding world can be seen all the time during game play. While Q1 measures the physical involvement in the game, Q2 measures how much the players forgot about the real world, which is more difficult when it can be seen all the time

\subsection{The egocentric error}

In each play session, the first two scenes asked the players to select the screen that showed the objects on the table as they saw them (in these cases, the NPC sits near the players and they have the same view on the table). In all the other scenes, the NPC sits at a different side of the table.

An egocentric error happens when the players select their own view instead of the NPC's, and usually a very high egocentric error rate is expected. According to Epley [40], the egocentric error 
is very frequent also in adults: they have simply learnt to correct the error better and in a shorter time. Epley states that adults tend to use themselves as standard when evaluating others, and they share with children an automatic egocentric default in perspective taking. Adults, with time, practice and experience have become better at correcting when necessary.

The data confirms this expectation: The graph in Figure 7, for each scene reports the first answers, showing the percentage of the correct answers, the egocentric errors and the other mistakes.

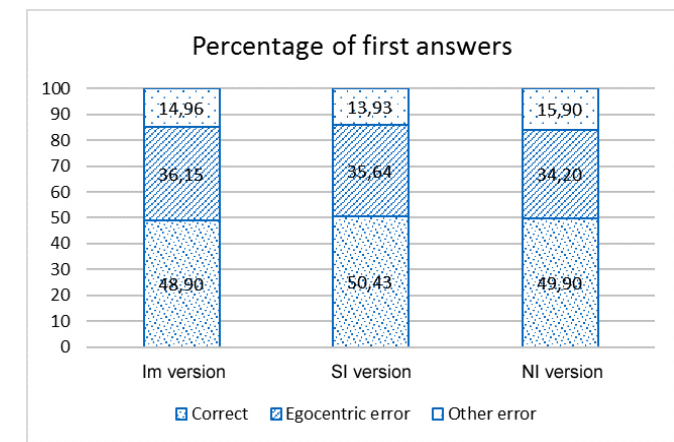

Figure 7. The percentage of first answers that are correct, egocentric errors and other types of errors

Overall, on average, only $49.74 \%$ of scenes had no error, while $35.33 \%$ of first answers were egocentric errors and only $14.93 \%$ were other errors.

The data from the first two scenes are somehow more surprising: $19.44 \%$ of children in scene one and $18.06 \%$ in scene two had difficulty in recognizing the picture representing the scene in front of them. This is an issue that deserves further investigation.

\subsection{Follow-up Experiment}

According to the results of the data analysis, having a tool that supports, through its interactivity, the embodied aspects of the SPT skill by allowing the players to move (even if in a virtual manner) in the environment where the scene is taking place, actually enhances the users' ability in the SPT skill. A new question arose from this analysis: is there a difference in performance when the ability is enacted in a real life environment?

In order to answer this question, in a follow-up session, the game was reproduced in a real context. All the scenes were re-built in a room, using twelve square tables on which real objects were placed (Figure 8). The objects were mostly the same as the ones used in the digital versions of the game. Some objects had to be replaced, in these cases the replacement was chosen so that it had the same characteristics with respect to the SPT skill.

The researcher played the role of the NPC: he sat at a chair previously placed at a side of the table and asked the participant to stand on a placeholder on the floor. Then, he showed the player four pictures of the table taken from the four sides and asked him to choose the picture that was taken from his own point of view. The researcher took note of the child's answers.

The follow-up experiment was done after a period of three months from the original experiment and 39 players participated. All the participants had already played with the other three versions of the same game, therefore were already aware of the required task. 


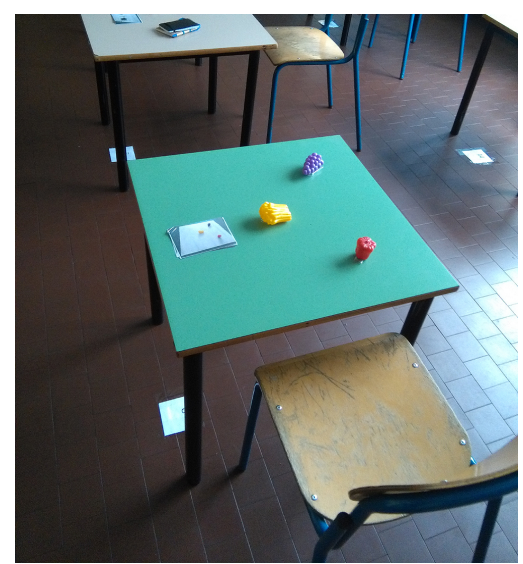

Figure 8. The real life version of the In Your Eyes game

We thus merged the data from the other three conditions and of this follow-up and tested a LMM. The effect of the immersion level was not statistically significant $(\mathrm{F}(3,75.00)=1.27, \mathrm{p}=$ .289). However, this analysis could have suffered from the limited sample size, which yielded relatively high standard errors (Figure 9).

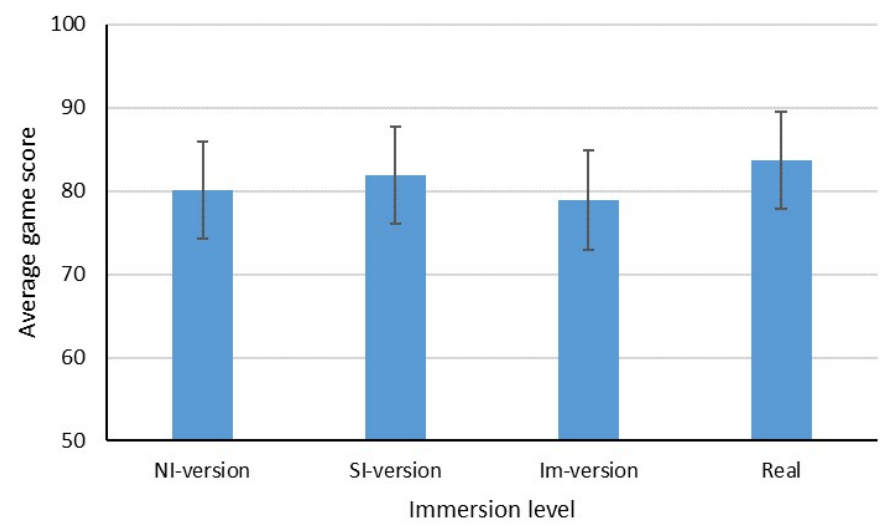

Figure 9. Average game score in follow-up data

Post-hoc tests revealed a marginally significant higher scores in the Real condition than in the Im-version $(\mathrm{p}=.08)$.

This result shows that, even though there is a slight advantage in using a real life setting, it is not statistically significant. On the other hand, the use of Virtual Reality (whatever level of immersion) gives the following advantages:

- Scene creation: the organization of a scene in real life is not so straightforward, it requires having the objects, putting them on the table and making the four pictures, avoiding to move the objects in any way, etc. Each single scene needs minutes to be set up while the computer can generate it in a few milliseconds, using a wide variety of objects and configurations.

- Portability: the game can be played anywhere, at any time and without the need to have another person performing the non-player character.

- Ease of use: the creation of the scene, the photos from the four sides of the table, the player's movements, etc. are difficult to manage correctly. Furthermore, in a "test" version the interaction with different experimenters would influence results.

- Data collection: the digital game automatically collects response times, errors, head and body movements, help requests. Not all this data would be available in a real life version of the game.

- The possibility to repeat the experiment: a digital version of the game guarantees the possibility to repeat the experiment with any users having exactly the same experimental conditions (same objects, same virtual room, etc.). 
The Virtual Reality setting well supports the SPT ability, while offering, at the same time, several advantages with respect to its flexibility and usability.

\section{Conclusions}

The present paper describes an experiment aimed at assessing the impact of immersion and the feeling of presence in a spatial reasoning task. A game based on the SPT ability was implemented with three different levels of immersion in a virtual world, and then tested with some grade three and four classes from a local primary school. A repeated measures design was chosen for the experiment, and balanced groups were defined based on a paper based pre-test, gender and age, in order to counterbalance order effects.

According to our hypothesis, a higher level of immersion should be related to better performances, but results did not fully support our hypothesis: while the NI-version showed lower game scores, the SI-version and the Im-version did not yield significantly different performances. This results suggested that immersion and presence do not seem to influence people's performance in a SPT task. However, they also imply that having the possibility to move in the virtual worlds and checking what the scene looks like from the NPC's point of view seems to have a positive impact on SPT performance. It should be noted that nearly all the players were at their first experience with the use of the HMD, therefore they may have shown some clumsiness due to the unknown interface, and this might have impaired their performance.

A follow-up trial was then carried out with a subset of the original participants, to measure the difference in performance between a game and a real life setting. Scores were marginally higher in the real life condition, but the difference was not significant.

Immersion presents some other drawbacks. One out of ten of our players could not manage to use the HMD for sickness reasons, and this is, at the current state of the art, a drawback for an extensive training intervention. Future studies may be needed to investigate the relation between sickness and other player characteristics as sex, age and the SPT ability. Furthermore, the HMD completely isolates the player from the surrounding world, limiting real life cooperation in the task. Finally, the limited availability of the tools and their costs make it very difficult to use them in formal educational contexts.

Summarizing, SPT is an embodied skill, and as such an advantage is measured when the players are allowed to move around the scene in order to enact the ability, while a completely theoretical approach as required in the non-immersive version causes lower scores. Nevertheless, no statistically significant difference was measured between the other two digital versions of the game and the one that took place in a real life environment. This implies that the virtual reality games well support the SPT ability, while allowing for much more flexibility and usability than the real life setting.

Generalizing, virtual reality appears to be a good environment for the enactment of spatial embodied abilities, while complete immersion has, at the present state of technology, still some difficulties. However, technology is evolving very fast and further experiments will be needed to assess new tools and verify their impact on the users' performance.

Teachers and students will find a great advantage in the use of virtual reality games and applications, but some care is needed in the selection of the correct system, and the more immersive is not necessarily the best choice.

A new experiment is undergoing at the present time, involving some classes of the last years of primary school (grades four and five, students ages 9-11), with the aim of supporting the consolidation of their spatial reasoning abilities and measuring their impact on school results in mathematics. The training sessions are based on the use of various digital games, among which the "In Your Eyes" game in its SI-version.

\section{References}

[1] Bonga, S. W. (2006). Evolution of Student Interest in Science and Technology Studies Policy Report. Organisation for Economic Co-operation and Development Global Science Forum. Avaliable at: http://www.oecd.org/science/sci-tech/36645825.pdf

[2] Rocard, M. (2007). Science Education Now: A Renewed Pedagogy for the Future of Europe. Brussel: High Level Group on Science Education, Directorate General for Research. Science, Economy and Science, European Commission. 
[3] Sinclair, N., \& Bruce, C. D. (2015). New opportunities in geometry education at the primary school. ZDM, 47(3), 319-329. https://doi.org/10.1007/s11858-015-0693-4

[4] Newcombe, N. S. (2010). Picture this: Increasing math and science learning by improving spatial thinking. American Educator, 34(2), 29.

[5] Uttal, D. H., Meadow, N. G., Tipton, E., Hand, L. L., Alden, A. R., Warren, C., \& Newcombe, N. S. (2013), The malleability of spatial skills: a meta-analysis of training studies. Psychological bulletin, 139(2), 352-402. https://doi.org/10.1037/a0028446

[6] Hainey, T., Connolly, T., Stansfield, M., \& Boyle, L. (2011). The use of computer games in education: A review of the literature. Handbook of research on improving learning and motivation through educational games: Multidisciplinary approaches, 29-50. https://doi.org/10.4018/978-1-60960-495-0.ch002

[7] De Aguilera, M., \& Mendiz, A. (2003). Video games and education: (Education in the Face of a "Parallel School"). Computers in Entertainment (CIE), 1(1), 1. https://doi.org/10.1145/950566.950583

[8] Gee, J. P. (2003). What video games have to teach us about learning and literacy. Computers in Entertainment (CIE), 1(1), 20-20. https://doi.org/10.1145/950566.950595

[9] Bransford, J., Brown, A., \& Cocking, R. (2000). How people learn: brain, mind, experience, and school. Washington DC: National Academy Press.

[10] Prensky, M. (2003). Digital game-based learning. Computers in Entertainment (CIE), 1(1), 21 21. https://doi.org/10.1145/950566.950596

[11] Silveira, I. F., de Araujo Jr, C. F., da Veiga, J. S., Bezerra, L. N. M., \& Kasperavicius, L. C. C. (2011). Building computer games as effective learning tools for digital natives-and similars. Issues in Informing Science \& Information Technology, 8, 77-93.

[12] Whitton, N. (2010). Learning with digital games. A practical guide to engaging students in higher education. New York, NY: Routledge.

[13] Amory, A., Naicker, K., Vincent, J., \& Adams, C. (1999). The use of computer games as an educational tool: identification of appropriate game types and game elements. British Journal of Educational Technology, 30(4), 311-321. https://doi.org/10.1111/1467-8535.00121

[14] Whitebread, D. (1997). Developing children's problem-solving: the educational uses of adventure games. Information technology and authentic learning. London: Routledge, 13-37.

[15] Bottino, R. M., \& Ott, M. (2006). Mind games, reasoning skills, and the primary school curriculum. Learning Media and Technology, 31(4), 359-375. https://doi.org/10.1080/17439880601022981

[16] Bottino, R. M., Ott, M., \& Tavella, M. (2013, January). Investigating the relationship between school performance and the abilities to play mind games. In European Conference on Games Based Learning. Academic Conferences International Limited.

[17] Bottino, R. M., Ferlino, L., Ott, M., \& Tavella, M. (2007). Developing strategic and reasoning abilities with computer games at primary school level. Computers \& Education, 49(4), 12721286. https://doi.org/10.1016/j.compedu.2006.02.003

[18] Freina, L., Bottino, R., Tavella, M., \& Dagnino, F. (2016). Immersion's Impact on Performance in a Spatial Reasoning Task. In R. Bottino, J. Jeruring, R.C. Veltkamp (Eds.), Games and Learning Alliance, Lecture Notes in Computer Science, LNCS 10056. Springer International Publishing, 211-220, doi: 10.1007/978-3-319-50182-6 https://doi.org/10.1007/978-3-319-50182-6

[19] Nichols, S., Haldane, C., \& Wilson, J. R. (2000). Measurement of presence and its consequences in virtual environments. International Journal of Human-Computer Studies, 52(3), 471-491. https://doi.org/10.1006/ijhc.1999.0343

[20] Dalgarno, B., \& Lee, M. J. (2010). What are the learning affordances of 3-D virtual environments?. British Journal of Educational Technology, 41(1), 10-32. https://doi.org/10.1111/j.1467-8535.2009.01038.x

[21] Rose, F. D., Attree, E. A., Brooks, B. M., Parslow, D. M., \& Penn, P. R. (2000). Training in virtual environments: transfer to real world tasks and equivalence to real task training. Ergonomics, 43(4), 494-511. https://doi.org/10.1080/001401300184378

[22] Newcombe, N. S., \& Frick, A. (2010). Early education for spatial intelligence: Why, what, and how. Mind, Brain, and Education, 4(3), 102-111. https://doi.org/10.1111/j.1751228X.2010.01089.X

[23] Kessler, K., \& Rutherford, H. (2010). The two forms of visuo-spatial perspective taking are differently embodied and subserve different spatial prepositions. Embodied and grounded cognition, 108. https://doi.org/10.3389/fpsyg.2010.00213

[24] Retz-Schmidt, G. (1988). Various views on spatial prepositions. AI magazine, 9(2), 95. 
[25] Surtees, A. D. R., Apperly, I. A., \& Samson, D. (2013). The use of embodied self-rotation for visual and spatial perspective-taking. Frontiers in human neuroscience, 7, 698, https://doi.org/10.3389/fnhum.2013.00698

[26] Piaget, J., and Inhelder, B. (1956). The Child's Conception of Space, Trans. F. J. Langdon and J. L. Lunzer. London: Routledge and Kegan Paul.

[27] Newcombe, N. (1989). The development of spatial perspective taking. Advances in child development and behavior, 22, 203-247. https://doi.org/10.1016/S0065-2407(08)60415-2

[28] Meyer, M. L., Salimpoor, V. N., Wu, S. S., Geary, D. C., \& Menon, V. (2010). Differential contribution of specific working memory components to mathematics achievement in 2 nd and 3rd graders. Learning and Individual Differences, 20(2), 101-109. https://doi.org/10.1016/j.lindif.2009.08.004

[29] Freina, L., \& Canessa, A. (2015, September). Immersive vs desktop virtual reality in game based learning. In ECGBL2015-9th European Conference on Games Based Learning: ECGBL2015 (Vol. 195). Academic Conferences and publishing limited.

[30] Bottino, R. M., Ott, M., \& Tavella, M. (2013). Scaffolding pedagogical planning and the design of learning activities: An on-line system. Governance, Communication, and Innovation in a Knowledge Intensive Society, 222. https://doi.org/10.4018/978-1-4666-4157-0.ch018

[31] Inagaki, H., Meguro, K., Shimada, M., Ishizaki, J., Okuzumi, H., \& Yamadori, A. (2002). Discrepancy between mental rotation and perspective-taking abilities in normal aging assessed by Piaget's three-mountain task. Journal of Clinical and Experimental Neuropsychology, 24(1), 18-25. https://doi.org/10.1076/jcen.24.1.18.969

[32] Tversky, B., \& Hard, B. M. (2009). Embodied and disembodied cognition: Spatial perspective-taking. $\quad$ Cognition, 110(1), 124-129. https://doi.org/10.1016/j.cognition.2008.10.008

[33] Desai, P. R., Desai, P. N., Ajmera, K. D., \& Mehta, K. (2014). A Review Paper on Oculus Rift-A Virtual Reality Headset. International Journal of Engineering Trends and Technology (IJETT), 13(4), 175-179. https://doi.org/10.14445/22315381/IJETT-V13P237

[34] Frick, A., Möhring, W., \& Newcombe, N. S. (2014). Picturing perspectives: development of perspective-taking abilities in 4-to 8-year-olds. Frontiers in psychology, 5, 386. https://doi.org/10.3389/fpsyg.2014.00386

[35] Slater, M., Usoh, M., \& Steed, A. (1994). Depth of presence in virtual environments. Presence: Teleoperators \& Virtual Environments, 3(2), 130-144. https://doi.org/10.1162/pres.1994.3.2.130

[36] Gibbons, R. D., Hedeker, D., and DuToit, S. (2010). Advances in analysis of longitudinal data. $\begin{array}{lllll}\text { Annual review of clinical } & \text { psychology. }\end{array}$ https://doi.org/10.1146/annurev.clinpsy.032408.153550

[37] Bates, D., Maechler, M., Bolker, B., \& Walker, S. (2014). lme4: Linear mixed-effects models using Eigen and S4. R package version, 1(7), 1-23. Available at: http://cran.rproject.org/package=lme4; 2014.

[38] Kuznetsova, A., Brockhoff, P. B., \& Christensen, R. B. (2014). lmerTest: Tests in Linear Mixed Effects Models. R package version 2.0-20. Available at: http://cran.rproject.org/package $=$ lmerTest.

[39] Tremblay, A., and Ransijn, J. (2014). LMERConvenienceFunctions: A suite of functions to back-fit fixed effects and forward-fit random effects, as well as other miscellaneous functions. $\mathrm{R}$ package version 2.5. Available at: http://cran.r-project.org/package= LMERConvenienceFunctions.

[40] Epley, N., Morewedge, C. K., \& Keysar, B. (2004). Perspective taking in children and adults: Equivalent egocentrism but differential correction. Journal of Experimental Social Psychology, 40(6), 760-768. https://doi.org/10.1016/j.jesp.2004.02.002 